\title{
The exhibition design of a House Museum: The Dining Room as a case study
}

\author{
Keywords \\ Design, Exhibition Design, House Museum, Material Culture.
}

The exhibition space of a Collector's House Museum, the specific case of the Ema Klabin House Museum (HMEK), offers the field of exhibition design a unique place for research due to its nature, which moves from the private to the public and presents artifacts that allow entering the biography of objects and understanding them from a material culture perspective. The present research, still in progress, has as a case study, the environment of the Dining Room at HMEK, which evokes, more than any other room, domesticity and the memory of home while at the same time convoking the experience of the museum space. The research proposes the centrality of the Dining Room both in the practices of the former residence and in the discursive elaboration of the current museum. In this context and in the proposal of this research, the study of the Dining Room, its materialities, uses and spatial organization in both historical moments is an exemplary case for the implementation of research in a house museum, serving its study, based on the indicated variables, to highlight possibilities in this type of institution based on its physicality. The former residence of collector, businesswoman and patron Ema Gordon Klabin houses a multicultural collection that encompasses visual arts, ethnographic objects, books, furniture and decorative arts, exhibited in preserved environments from a house register with exhibition design that highlights the practices of the house, collector and building of modernized classical architecture. It is considered that artifacts are memory supports, vectors capable of preserving or reviving them, provoking relationships between what has been experienced and the situations of the present time. The Dining Room, used for diplomatic and social purposes, is a space measuring $4.80 \mathrm{~m} \times 5.30 \mathrm{~m}$ and connects to the social rooms of the house with a large glass door accessing the external patio, environment with tropical plants and an Italian fountain. It is accessed through a gallery - a must-see for visitors to the house and now, to the museum - and the living room. On the opposite wall, a camouflaged door accesses the kitchen and service areas currently the museum's reception area - where the French service was carried out. Currently, the Dining Room is organized in accordance with photographs and other historical records that attest to its use before its change to museum status. It exhibits documents and objects that attest to the memory of the uses and customs of this space, for example, the Reception Book, in which the hostess described each event, her guests and the planning of the reception. The research proposes an understanding of the cultural trajectory of objects and the implication of design in the activation of private memories of a domestic environment that, by becoming a museological space, provokes collective memories through its exhibition design, investigating the application of design to address the feedback between experience and history. 